\title{
Design Optimization of Controller Parameters Used in Variable Speed Wind Energy Conversion System by Genetic Algorithms
}

\author{
Hany M. Hasanien, Senior Member, IEEE, and S. M. Muyeen, Senior Member, IEEE
}

\begin{abstract}
This paper presents an optimum design procedure for the controller used in the frequency converter of a variable speed wind turbine (VSWT) driven permanent magnet synchronous generator (PMSG) by using genetic algorithms (GAs) and response surface methodology (RSM). The cascaded control is frequently used in the control of the frequency converter using the proportional plus integral (PI) controllers. The setting of the parameters of the PI controller used in a large system is cumbersome, especially in an electrical power system, which is difficult to be expressed by a mathematical model or transfer function. This study attempts to optimally design the parameters of the PI controllers used in the frequency converter of a variable speed wind energy conversion system (WECS). The effectiveness of the designed parameters using GAs-RSM is then compared with that obtained using a generalized reduced gradient (GRG) algorithm considering both symmetrical and unsymmetrical faults. The permanent fault condition due to unsuccessful reclosing of circuit breakers is considered as well. It represents another salient feature of this study. It is found that fault-ride-through of VSWT-PMSG can be improved considerably using the parameters of its frequency converter obtained from GAs-RSM.
\end{abstract}

Index Terms-Fault-ride-through, frequency converter, genetic algorithms (GAs), permanent magnet synchronous generator (PMSG), response surface methodology (RSM), wind energy conversion system (WECS).

\section{INTRODUCTION}

W IND energy has continued its growth worldwide in recent years. Over the past ten years, the global wind power capacity has continued to grow at an average cumulative rate of over $30 \%$, and 2008 was another record year with more than $27 \mathrm{GW}$ of new installations, bringing the total up to over $120 \mathrm{GW}$ [1]. Therefore, analysis of the transient and fault voltage ride through (FRT) characteristics of the wind turbine generator system (WTGS) is needed, as a huge number of wind generators will be connected to the existing network in the near future.

Recent wind farm grid codes emphasized fault-ride-through characteristics of the wind generators [2], [3]. Transient stability

Manuscript received January 17, 2011; revised December 08, 2011; accepted January $02,2012$.

H. M. Hasanien is with the Electrical Power and Machines Department, Faculty of Engineering, Ain Shams University, Cairo 11517, Egypt (e-mail: hanyhasanien@ieee.org).

S. M. Muyeen is with the Electrical Engineering Department, The Petroleum Institute, Abu Dhabi 2533, U.A.E.. analysis for fixed speed wind generators has been presented in much of the literature [4]-[7]. With variable speed wind energy conversion system (WECS) stability, control, and FRT analyses have been reported for the doubly fed induction generator (DFIG) [8]-[12], wound field synchronous generator (WFSG) [13], [14], switched reluctance generator (SRG) [15], and permanent magnet synchronous generator (PMSG) [16]-[22]. Recently, permanent magnet machines are becoming very popular in wind power application. In PMSG, the excitation is provided by permanent magnets instead of the field winding. Permanent magnet machines are characterized as having large air gaps, which reduce flux linkage even in machines with multimagnetic poles [23], [24]. As a result, low rotational speed generators can be manufactured with relatively small sizes with respect to its power rating. Moreover, the gearbox can be omitted due to the low rotational speed in the PMSG wind generation system, resulting in lower cost. In a recent survey, the gearbox was found to be the most critical component, since its downtime per failure is high in comparison to other components in the WTGS [25].

The variable speed wind turbine (VSWT) driven PMSG is connected to the grid through a full-scale frequency converter. The classical controllers are, in general, used in the control of the generator- and grid-side converter/inverter. Classical control theory suffers from some limitations due to the assumptions made in designing the control systems such as linearity, time-invariance, etc. Essentially, the conventional proportional plus integral (PI) and proportional plus integral plus derivative (PID) controllers have been utilized in many control applications due to the robustness of these controllers and the fact that they offer a wide stability margin. However, the conventional PI and PID controllers are very sensitive to parameter variations and the nonlinearity of dynamic systems. The setting of the parameters of the PI controller used in a large system is cumbersome, especially when required to apply in electric power system which is difficult to be expressed by a mathematical model or transfer function. To achieve the FRT in the case of VSWT-PMSG, the PI controllers used in the converter/inverter should be tuned properly. Optimal design of the controller parameters used in the frequency converter of VSWT-PMSG has so far not been reported in power system literature.

In this study, response surface methodology (RSM) and genetic algorithms (GAs) are proposed to optimally design the parameters of the controllers used in the frequency converter of VSWT-PMSG to augment the FRT capability of wind farms. This is the novel feature of this study. Three-level frequency 
converter topology is used in the simulation as it is suitable for high power application [26]. The effectiveness of the designed parameters using GAs-RSM is then compared with that obtained using the generalized reduced gradient (GRG) algorithm considering both symmetrical and unsymmetrical faults. The circuit breakers (CBs) are usually reclosed automatically on overhead transmission lines in the grid to improve the service continuity. The reclosure may be either high-speed or with time delay. High-speed reclosure refers to the closing of CBs after a time just long enough to permit fault-arc deionization. However, high-speed reclosure is not always acceptable. Reclosure into a permanent fault or an unsuccessful reclosing may cause system instability. Thus, the application of automatic reclosing is usually constrained by the possibility of a persistent fault, which would create a second fault after reclosure. The analysis of permanent fault due to unsuccessful reclosing of CBs is another salient feature of this study. The FRT analysis is performed in the light of recent wind farm grid codes mentioned earlier. The organization of the paper is given as follows.

In Section II, the wind turbine modeling is described briefly. Section III describes the wind farm model system. In Section IV, modeling and control of the frequency converter used in VSWTPMSG are presented. Section V elaborately describes the optimal design methodology of controllers used in the frequency converter. In Section VI, the proposed optimization procedure is presented. Section VII presents the simulation results and discussion. Finally, Section VIII draws the conclusion.

The simulation analyses for the grid connected wind farm are carried out using the laboratory standard power system simulator PSCAD/EMTDC. Moreover, MATLAB is used for design optimization of controller parameters. Finally, it is concluded that the proposed optimum design procedure presented in this study is very much effective to determine the parameters of controllers used in the frequency converter of VSWT-PMSG to achieve the FRT capability of wind farm during a network disturbance.

\section{WIND TURBINE MODELING}

The mathematical relation for the mechanical power extraction from the wind can be expressed as follows [27]:

$$
P_{w}=0.5 \rho \pi R^{2} V_{w}^{3} C_{P}(\lambda, \beta)
$$

where $P_{w}$ is the extracted power from the wind, $\rho$ is the air density $\left[\mathrm{kg} / \mathrm{m}^{3}\right], R$ is the blade radius $[\mathrm{m}], V_{w}$ is the wind speed $[\mathrm{m} / \mathrm{s}]$, and $C_{p}$ is the power coefficient which is a function of tip speed ratio, $\lambda$, and blade pitch angle, $\beta$ [deg.]. The turbine characteristics used are shown in Fig. 1. [27], [28].

\section{Wind FARM Model System}

The aggregated wind farm model is considered herein where many small size wind generators can be represented with a large capacity wind generator [29]. The model system used in the FRT characteristic analyses of VSWT-PMSG is shown in Fig. 2, where PMSG is connected to an infinite bus through the frequency converter, a step-up transformer, and double circuit transmission line. The parameters of PMSG used in the simulation are shown in Table I [30]. The system base is 5.0 MVA. The short circuit MVA is considered as 16.67.

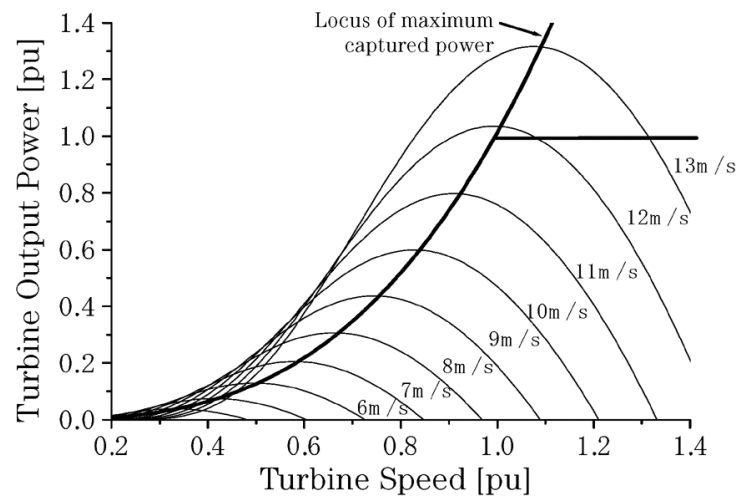

Fig. 1. Turbine characteristics with maximum power point tracking.

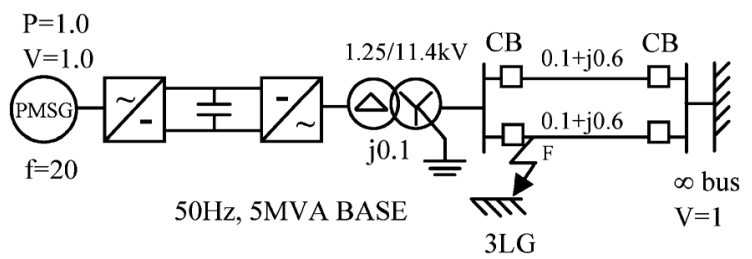

Fig. 2. Model system.

TABLE I

GENERATOR PARAMETERS

\begin{tabular}{|l|l|l|l|}
\hline Rated Power & $5[\mathrm{MW}]$ & Stator Resistance & $0.01[\mathrm{pu}]$ \\
\hline Rated Voltage & $1.0[\mathrm{kV}]$ & d-axis Reactance & $1.0[\mathrm{pu}]$ \\
\hline Frequency & $20[\mathrm{~Hz}]$ & q-axis Reactance & $0.7[\mathrm{pu}]$ \\
\hline Number of Poles & 150 & Field Flux & $1.4[\mathrm{pu}]$ \\
\hline H & $3.0[\mathrm{~s}]$ & & \\
\hline
\end{tabular}

\section{Modeling And Control of Frequency Converter}

The electrical scheme of VSWT-PMSG topology used in this study is shown in Fig. 3. The frequency converter consists of a generator-side ac/dc converter, a dc-link capacitor, and a grid-side dc/ac inverter. Three-level (3L) neutral-point clamped (NPC) topology is considered for both the converter and inverter, as shown in Fig. 3. The 3L converter has the advantages that the blocking voltage of each switching device is one half of the dc-link voltage in contrast to the full dc-link voltage in the case of the two-level converter, and the harmonic contents of the $3 \mathrm{~L}$ converter output voltage is much less than those of the two-level one, at the same switching frequency.

For both the converter/inverter, the well-known cascaded control is considered in this study as explained in [21] and [30]. The insulated gate bipolar transistor (IGBT) switching table for 3L NPC-based voltage source converter/inverter is shown in Table II. The gate signal generation scheme for the IGBT devices used in converter/inverter is shown in Fig. 4. The carrier frequency for an inverter is chosen $1050 \mathrm{~Hz}$. The reference value of the controller shown in Fig. 4 is determined from the cascaded control. The generator-side converter ensures the maximum power point tracking control along with unity power factor operation at the generating side. The grid-side inverter controls the dc-link voltage and maintains the voltage of the grid side as well, at the desired level set by the network operator. During a severe network disturbance such as short circuit fault, the front end inverter connected directly to the grid has to provide sufficient reactive current to support the grid. At the same time, as the grid voltage collapses, real power 


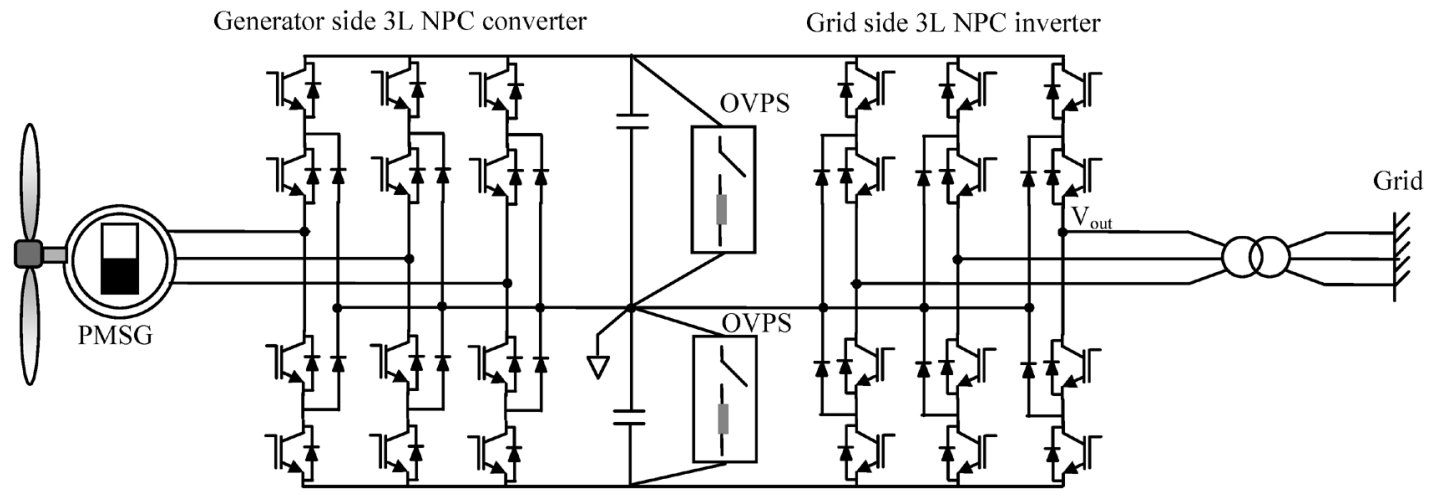

Fig. 3. Electrical scheme of VSWT-PMSG.

TABLE II

IGBT SWITCHING TABLE

\begin{tabular}{|c|c|c|c|}
\hline $\mathrm{V}_{\text {out }}$ & $+\mathrm{V}_{\mathrm{dc}}$ & 0 & $-\mathrm{V}_{\mathrm{dc}}$ \\
\hline SW1 & 1 & 0 & 0 \\
\hline SW2 & 1 & 1 & 0 \\
\hline SW3 & 0 & 1 & 1 \\
\hline SW4 & 0 & 0 & 1 \\
\hline
\end{tabular}

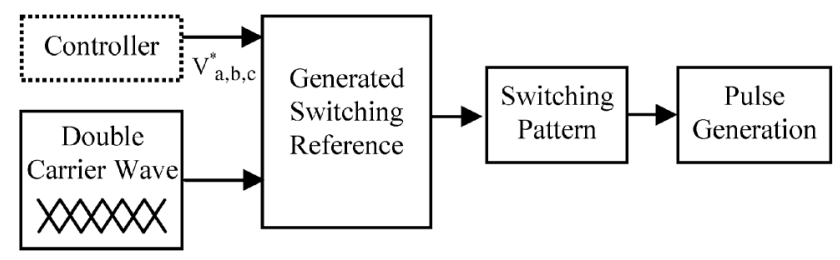

Fig. 4. Gate signal generation scheme.

cannot be transmitted to the grid side. As a result, the dc voltage of the dc-link capacitor increases rapidly, which impedes the normal operation of the frequency converter unit. Therefore, an over voltage protection scheme (OVPS) using the braking chopper is taken into consideration in this study as shown in Fig. 3. The braking chopper is modeled in the dc-link in order to protect the dc-link capacitor during fault conditions. The chopper is activated when the dc-link voltage increases over the predefined limit. It dissipates the active power in the resistance during the voltage dip in the grid.

In this study, as the fault-ride-through of VSWT-PMSG is emphasized, the control of the grid-side inverter and parameters optimization using RSM and GAs are demonstrated in the light of the grid-side inverter. The simplified cascaded control scheme used in the analysis is shown in Fig. 5. The details of the optimization method are presented as follows.

\section{Optimal Design}

\section{A. The RSM}

Recently, the RSM has received a great potential for modeling, analyzing, and optimizing the design of many electromagnetic devices. This method is a statistical tool used to build an empirical model by finding the relationship between the design variables and response through the statistical fitting method [31].
In this study, the system analysis on a laboratory standard power system simulation package PSCAD/EMTDC [32] is used as numerical simulations to provide the response. The maximum percentage undershoot (MPUS), maximum percentage overshoot (MPOS), settling time $\left(T_{s}\right)$, and steady-state error $\left(E_{s s}\right)$ of the voltage profile are considering the responses. Those are changed by the design variables variant. The second-order model of the RSM is used in this study for obtaining a more accurate response. The creation of the response surface is based on the central composite design (CCD). The CCD has been widely used for fitting the second-order response surface [31], [33].

\section{B. GA Method}

The GAs are powerful search techniques used in many engineering studies to find the solution of optimization problems [34]. GAs have been widely applied for solving the optimization problems of electrical power systems. The heuristic search of GAs is based on the principle of survival of the fittest [35]. Generally, GAs start the optimization process with random generation of a population, which consists of a set of chromosomes. Once the random population is achieved, the solution represented by each string should be evaluated. The fitness or objective function is the function responsible for evaluation of the solution at each step. The objective of this analysis is to minimize the MPUS of the voltage $\left(Y_{1}\right)$. In this study, the Rank fitness scaling is applied to avoid premature convergence. Moreover, GAs use techniques inspired by evolutionary biology such as natural selection, mutation, and crossover. There are many selection techniques in GAs. In this study, the process is carried out using the uniform selection technique, which exhibits no bias and minimal spread.

\section{OPTIMIZATION PROCEDURE}

Fig. 6 shows the flowchart of overall design strategy. The design procedure is described as follows [31]:

Step 1) Selection of Variables and Levels:

In this study, the proportional gain and integral time constant of the PI controllers shown in Fig. 5 are selected to be the design variables. $X_{1}$ is the proportional gain of PI-1, $X_{2}$ is the integral time constant of $\mathrm{PI}-1, X_{3}$ is the proportional gain of $\mathrm{PI}-2$, and $X_{4}$ is the integral time constant of PI-2. These variables have three levels. Level 1 represents the minimum value of the design variable, level 2 is the average value, and 


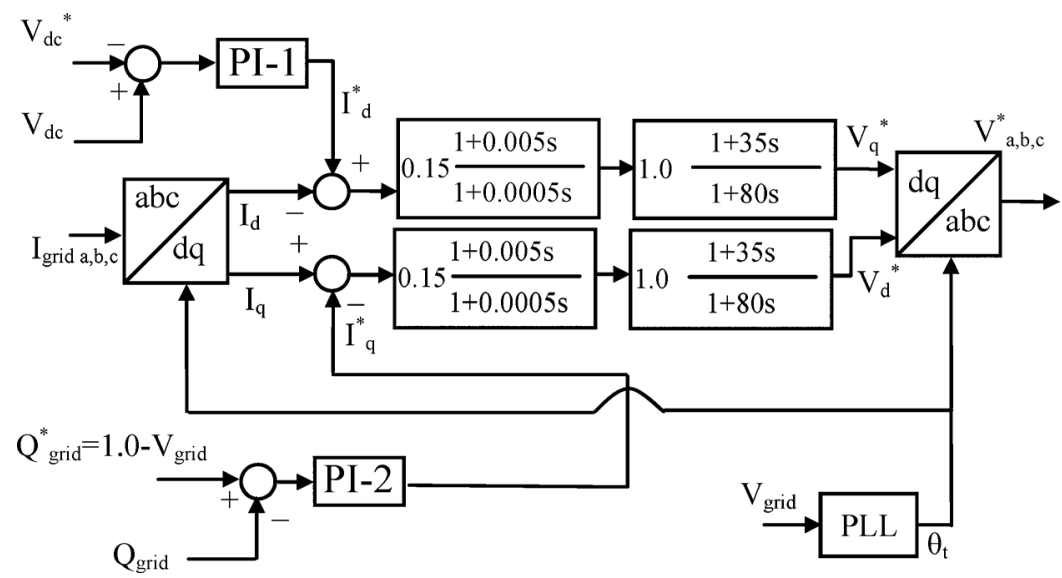

Fig. 5. Control block diagram for the grid-side 3L NPC inverter.

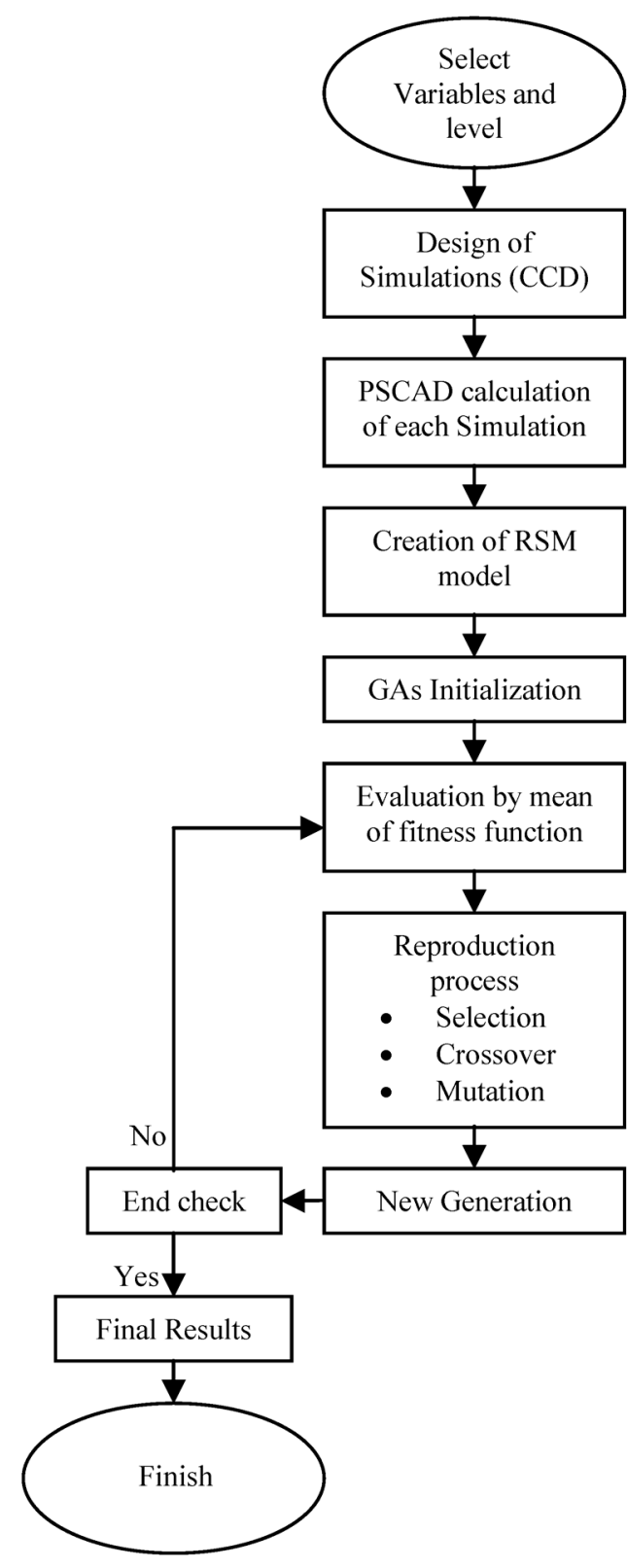

Fig. 6. Flowchart of optimum design process.

level 3 is the maximum value of the design variable [33]. Table III shows the design variables and levels.
TABLE III

DESIGN VARIABLES AND LEVELS

\begin{tabular}{|c|c|c|c|c|}
\hline $\begin{array}{c}\text { Design variables } \\
\text { Level }\end{array}$ & $X_{1}$ & $X_{2}$ & $X_{3}$ & $X_{4}$ \\
\hline $1(-1)$ & 0.5 & 0.2 & 0.5 & 0.2 \\
\hline $2(0)$ & 2.75 & 0.5 & 2.75 & 0.5 \\
\hline $3(1)$ & 5 & 0.8 & 5 & 0.8 \\
\hline
\end{tabular}

Step 2) Design of Simulations:

The range of design variables and simulation frequency is established by using the $\mathrm{CCD}$ as shown in Table IV. In this analysis, the experiment frequency of the CCD algorithm is set to 31 [36].

Step 3) PSCAD Program Calculation:

The PSCAD program calculation is performed for each simulation and the values of MPUS, MPOS, $T_{s}$, and $E_{s s}$ of the voltage profile are stored in a look-up table as given here in Table IV.

Step 4) Creation of Response Surface Empirical Model:

The purpose of this paper is to minimize the MPUS $\left(Y_{1}\right)$ with constraints of MPOS $\left(Y_{2}\right), T_{s}\left(Y_{3}\right)$, and $E_{s s}\left(Y_{4}\right)$. The four fitted second-order polynomial functions are found as follows:

$$
\begin{aligned}
Y_{1}= & 87.8292+0.0472 x_{1}-0.0583 x_{2} \\
& -0.3194 x_{3}+0.0639 x_{4}-0.1344 x_{1} x_{2} \\
& +0.0594 x_{1} x_{3}-0.0594 x_{1} x_{4}+0.0281 x_{2} x_{3} \\
& -0.1031 x_{2} x_{4}+0.0531 x_{3} x_{4}-0.3633 x_{1}^{2} \\
& +0.0367 x_{2}^{2}+0.2367 x_{3}^{2}+0.2367 x_{4}^{2} \\
Y_{2}= & 5.8196+0.6472 x_{1}+0.0139 x_{2} \\
& -1.8972 x_{3}-0.4083 x_{4}+0.0156 x_{1} x_{2} \\
& +0.2031 x_{1} x_{3}-0.3219 x_{1} x_{4}-0.0219 x_{2} x_{3} \\
& +0.0531 x_{2} x_{4}+0.1656 x_{3} x_{4}-0.5925 x_{1}^{2} \\
& -0.0925 x_{2}^{2}+0.2075 x_{3}^{2}+0.7075 x_{4}^{2} \\
Y_{3}= & 4.0339-1.7883 x_{1}+0.1111 x_{2} \\
& +0.6044 x_{3}+0.5989 x_{4}-0.0625 x_{1} x_{2} \\
& -0.7675 x_{1} x_{3}-0.0925 x_{1} x_{4}-0.0125 x_{2} x_{3} \\
& +0.1125 x_{2} x_{4}-0.2675 x_{3} x_{4}+1.5282 x_{1}^{2} \\
& -0.5068 x_{2}^{2}-0.1068 x_{3}^{2}+0.4432 x_{4}^{2}
\end{aligned}
$$


TABLE IV

RANGE OF DESIGN VARIABLES AND EXPERIMENT FREQUENCY

\begin{tabular}{|c|c|c|c|c|c|c|c|c|}
\hline Exp. & $X_{I}$ & $X_{2}$ & $X_{3}$ & $X_{4}$ & $\begin{array}{c}\text { MPUS } \\
(\%)\end{array}$ & $\begin{array}{c}\text { MPOS } \\
(\%)\end{array}$ & $\begin{array}{l}\text { Ts } \\
(s)\end{array}$ & $\begin{array}{l}\text { Ess } \\
(\%)\end{array}$ \\
\hline 1 & -1 & -1 & -1 & -1 & 88.3 & 8.2 & 4.86 & 0.92 \\
\hline 2 & 1 & -1 & -1 & -1 & 88.6 & 9.4 & 3.2 & 0.7 \\
\hline 3 & -1 & 1 & -1 & -1 & 88.3 & 8.2 & 4.16 & 0.8 \\
\hline 4 & 1 & 1 & -1 & -1 & 88.1 & 8.8 & 3.3 & 0.7 \\
\hline 5 & -1 & -1 & 1 & -1 & 86.6 & 3.5 & 8.2 & 1.5 \\
\hline 6 & 1 & -1 & 1 & -1 & 88.0 & 6.0 & 3.0 & 0.4 \\
\hline 7 & -1 & 1 & 1 & -1 & 88.0 & 3.0 & 8.5 & 1.6 \\
\hline 8 & 1 & 1 & 1 & -1 & 87.5 & 5.9 & 3.1 & 0.39 \\
\hline 9 & -1 & -1 & -1 & 1 & 88.4 & 7.0 & 6.2 & 1.02 \\
\hline 10 & 1 & -1 & -1 & 1 & 88.3 & 7.5 & 4.2 & 0.82 \\
\hline 11 & -1 & 1 & -1 & 1 & 88.25 & 6.9 & 7.5 & 1.3 \\
\hline 12 & 1 & 1 & -1 & 1 & 88.3 & 7.6 & 4.3 & 0.75 \\
\hline 13 & -1 & -1 & 1 & 1 & 88.0 & 3.8 & 8.5 & 1.6 \\
\hline 14 & 1 & -1 & 1 & 1 & 88.0 & 4.1 & 4.0 & 0.83 \\
\hline 15 & -1 & 1 & 1 & 1 & 87.4 & 3.5 & 8.8 & 1.6 \\
\hline 16 & 1 & 1 & 1 & 1 & 87.5 & 4.05 & 3.9 & 0.45 \\
\hline 17 & -1 & 0 & 0 & 0 & 87.6 & 3.7 & 807 & 1.5 \\
\hline 18 & 1 & 0 & 0 & 0 & 87.4 & 6.1 & 3.6 & 0.4 \\
\hline 19 & 0 & -1 & 0 & 0 & 88.0 & 4.5 & 3.5 & 0.41 \\
\hline 20 & 0 & 1 & 0 & 0 & 87.8 & 6.3 & 4.1 & 0.4 \\
\hline 21 & 0 & 0 & -1 & 0 & 88.2 & 7.9 & 3.9 & 0.41 \\
\hline 22 & 0 & 0 & 1 & 0 & 88.0 & 3.5 & 4.5 & 0.5 \\
\hline 23 & 0 & 0 & 0 & -1 & 87.9 & 5.6 & 3.9 & 0.4 \\
\hline 24 & 0 & 0 & 0 & 1 & 88.3 & 6.8 & 5.6 & 0.8 \\
\hline 25 & 0 & 0 & 0 & 0 & 87.8 & 6.1 & 3.8 & 0.43 \\
\hline 26 & 0 & 0 & 0 & 0 & 87.8 & 6.1 & 3.8 & 0.43 \\
\hline 27 & 0 & 0 & 0 & 0 & 87.8 & 6.1 & 3.8 & 0.43 \\
\hline 28 & 0 & 0 & 0 & 0 & 87.8 & 6.1 & 3.8 & 0.43 \\
\hline 29 & 0 & 0 & 0 & 0 & 87.8 & 6.1 & 3.8 & 0.43 \\
\hline 30 & 0 & 0 & 0 & 0 & 87.8 & 6.1 & 3.8 & 0.43 \\
\hline 31 & 0 & 0 & 0 & 0 & 87.8 & 6.1 & 3.8 & 0.43 \\
\hline
\end{tabular}

$Y_{4}=0.4503-0.3556 x_{1}-0.0117 x_{2}$

$+0.0806 x_{3}+0.0978 x_{4}-0.045 x_{1} x_{2}$

$-0.1975 x_{1} x_{3}-0.0025 x_{1} x_{4}-0.0237 x_{2} x_{3}$

$-0.0087 x_{2} x_{4}-0.0112 x_{3} x_{4}+0.4760 x_{1}^{2}$

$-0.0690 x_{2}^{2}-0.019 x_{3}^{2}+0.126 x_{4}^{2}$

Step 5) GA Optimization:

GAs can then work directly on this model, and in this study, MATLAB optimization Toolbox is considered [37]. The MPUS of voltage is the fitness func-
TABLE V

GAs CHARACTERISTICS

\begin{tabular}{|c|c|}
\hline \multicolumn{2}{|c|}{ GAs Parameters } \\
\hline Population type & Double vector \\
\hline Population size & 100 \\
\hline $\begin{array}{c}\text { Fitness scaling } \\
\text { function }\end{array}$ & Rank \\
\hline Selection function & Uniform \\
\hline Crossover fraction & 0.8 \\
\hline Crossover function & Scattered \\
\hline Migration fraction & 0.2 \\
\hline Migration interval & 20 \\
\hline
\end{tabular}

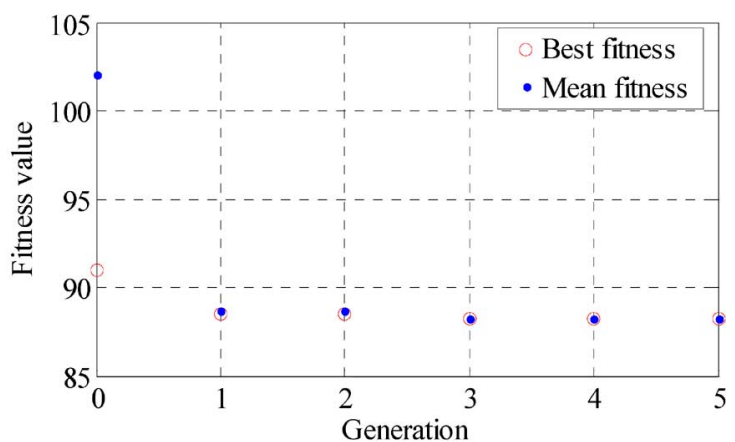

(a)

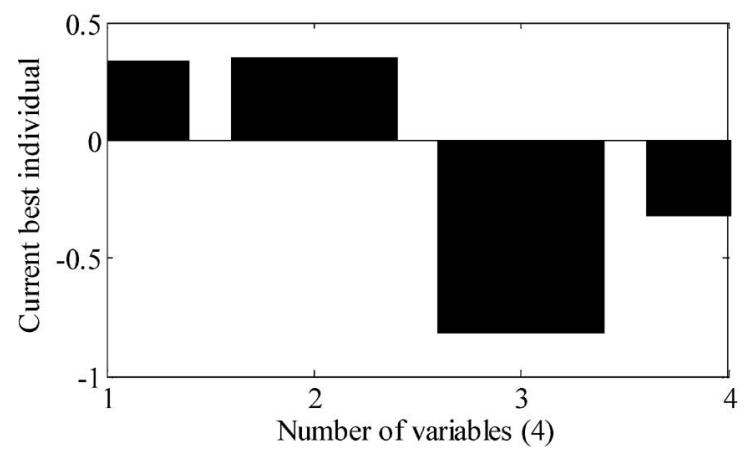

(b)

Fig. 7. (a) Fitness function value at each generation. (b) Current best individual.

TABLE VI

Optimal LeVEl AND SIZE OF DESIGN VARIABLES USING GAs

\begin{tabular}{|c|c|c|c|c|}
\hline $\begin{array}{c}\text { Design variables } \\
\text { Level }\end{array}$ & $X_{1}$ & $X_{2}$ & $X_{3}$ & $X_{4}$ \\
\hline Optimum level & 0.338 & 0.35 & -0.818 & -0.32 \\
\hline Optimum size & 3.51 & 0.605 & 0.908 & 0.4 \\
\hline
\end{tabular}

tion, and MPOS, $T_{s}$, and $E_{s s}$ are considered nonlinear constraint functions. The constraints of the optimized problem are described as follows:

- Design variables range is $0.5 \leq X_{1} \leq 5,0.2 \leq$ $X_{2} \leq 0.8,0.5 \leq X_{3} \leq 5$, and $0.2 \leq X_{4} \leq 0.8$.

- The MPOS constraint $Y_{2} \leq 8 \%, T_{s}$ constraint $Y_{3} \leq 3 \mathrm{~s}$, and $E_{s s}$ constraint $Y_{4} \leq 1.2 \%$.

Table V shows the GAs characteristics. After the fifth iteration, the GAs optimization was terminated, where the average change in the fitness value and the constraint violation were less than $1 e-6$. Fig. 7 shows the fitness function value at each generation and current best individual. Table VI shows the op- 


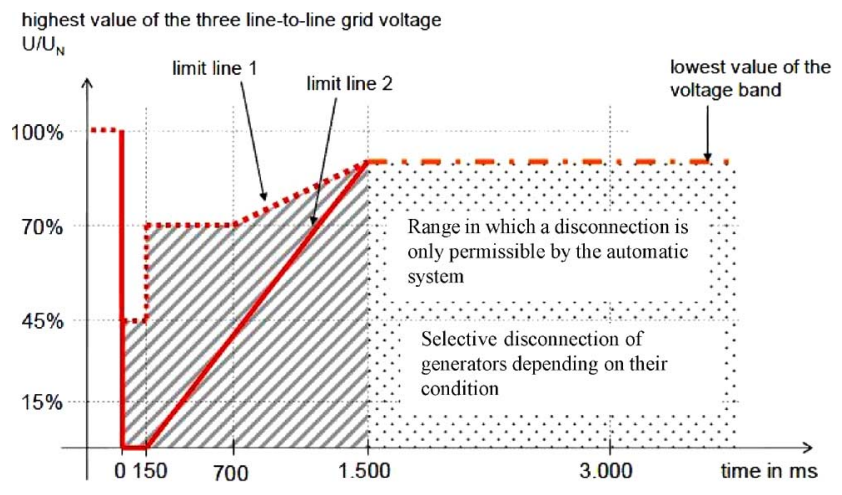

Fig. 8. Fault-ride-through standard set by E. On Netz [2].

timal level and size value of $X_{1}, X_{2}, X_{3}$, and $X_{4}$. At these optimal values, the MPUS equals $88.21 \%$, the MPOS is $7.88 \%, T_{s}$ is $3 \mathrm{~s}$, and $E_{s s}$ is $0.32 \%$.

\section{Simulation ANALYSIS AND Discussion}

A detailed switching model is considered in the 3L NPCbased converter/inverter to obtain a realistic response. Time-domain simulation has been done using PSCAD/EMTDC. The time step is chosen as $0.00001 \mathrm{~s}$. It is assumed that wind speed is constant and equivalent to the rated speed. This is because it may be considered that wind speed does not change dramatically during the short time interval of the simulation for the FRT characteristic analysis.

The wind farm grid code is fairly important to analyze the transient characteristics of WTGS. The wind farm grid codes are more or less similar in different countries with minor variations in voltage dip magnitude, fault time, voltage recovery time, etc., for the case of fault-ride-through standards. In this study, the simulation results are described in light of the recent grid code, set by E. On Netz, recently known as TenneT TSO GmbH. The FRT requirement is imposed on a wind power generator so that it remains stable and connected to the network during the network faults. The disconnection of the wind farm from the grid may worsen a critical grid situation and can threaten the security standards when the wind penetration is high. In Germany, wind generating plants are expected to acquit themselves during a low voltage disturbance as summarized in a voltage versus time curve shown in Fig. 8. Wind turbines are required to stay on the grid above the limit lines [2], [3]. Two cases are considered to validate the effectiveness of the control strategy using optimum values of frequency converter by using RSM-GAs methodology as explained in Section VI. To validate the effectiveness of the proposed RSM-GA-based optimization method, a comparison is carried out by the GRG algorithm. The GRG is one of the conventional optimization techniques used in electric power systems. This optimization technique is carried out using MATLAB Optimization Toolbox [37]. In the GRG method, the solver solves an objective attainment optimization problem. The derivatives are approximated by the solver in the objective function. Table VII shows the GRG characteristics. After 400 iterations, the GRG optimization was terminated, where the average change in the fitness value and the constraint violation were less than $1 e-6$. Table VIII shows the optimal level and size value
TABLE VII

GRG CHARACTERISTICS

\begin{tabular}{|c|c|}
\hline No. of iterations & 400 \\
\hline Fitness function tolerance & $1 \mathrm{e}-6$ \\
\hline User-supplied derivatives & Hessian Sparsity Pattern \\
\hline $\begin{array}{c}\text { Minimum perturbation in } \\
\text { derivatives }\end{array}$ & $1 \mathrm{e}-8$ \\
\hline $\begin{array}{c}\text { Maximum perturbation in } \\
\text { derivatives }\end{array}$ & 0.1 \\
\hline
\end{tabular}

TABLE VIII

Optimal LeVel AND Size of Design VARIABLES Using THE GRG ALGORITHM

\begin{tabular}{|c|c|c|c|c|}
\hline $\begin{array}{c}\text { Design variables } \\
\text { Level }\end{array}$ & $X_{1}$ & $X_{2}$ & $X_{3}$ & $X_{4}$ \\
\hline Optimum level & 0.85 & 0.6 & -0.82 & -0.95 \\
\hline Optimum size & 4.66 & 0.68 & 0.905 & 0.215 \\
\hline
\end{tabular}

of $X_{1}, X_{2}, X_{3}$, and $X_{4}$ using the GRG algorithm. At these optimal values, the MPUS equals $88.24 \%$, the MPOS is $8.88 \%, T_{s}$ is $3.17 \mathrm{~s}$, and $E_{s s}$ is $0.53 \%$. The simulation results are explained as follows.

\section{A. During Successful Reclosing of CBs}

In this case, the severe symmetrical three-line to ground fault (3LG) is considered as the network disturbance. The fault occurs at $0.1 \mathrm{~s}$ at fault point $F$, shown in Fig. 2. The CBs on the faulted lines are opened at $0.25 \mathrm{~s}$, and at $1.05 \mathrm{~s}$ the CBs are reclosed.

The grid-side inverter can provide necessary reactive power during the network disturbance. Therefore, the terminal voltage can return back at its prefault level as shown in Fig. 9(a). From Fig. 9(a), it can be realized that the terminal voltage response when GAs-RSM is used, is a better damped response than that obtained when the GRG approach is considered. The results also prove that using the parameters obtained from GAs-RSM, the system will even work well in the steady-state condition. The response of PMSG rotor speed is shown in Fig. 9(b). The real and reactive power responses of the grid are shown in Fig. 9(c) and (d), respectively. The dc-link voltage response is shown in Fig. 9(e). Due to the dc-link over voltage protection circuit as mentioned in Section IV, the dc-link voltage can be maintained within an acceptable range. The response of current through braking chopper is shown in Fig. 9(f).

For further verification of the proposed methodology, the transient analysis is carried out considering an unsymmetrical fault (single-line to ground, 1LG), using the proposed GAs-RSM and GRG algorithm. In this case also, the terminal voltage response using GAs-RSM is found better damped than that obtained using GRG approach, as shown in Fig. 10. The MPUS is slightly reduced as well. It can also be claimed from the simulation results that GAs-RSM works well for both symmetrical and unsymmetrical fault conditions and hence the FRT of a wind farm can be improved using the controller parameters obtained from GAs-RSM.

\section{B. During Unsuccessful Reclosing of CBs}

In this section, it is assumed that a $3 \mathrm{LG}$ fault occurs at point $F$ in Fig. 2. The fault occurs at $0.1 \mathrm{~s}$. The CBs on the faulted 


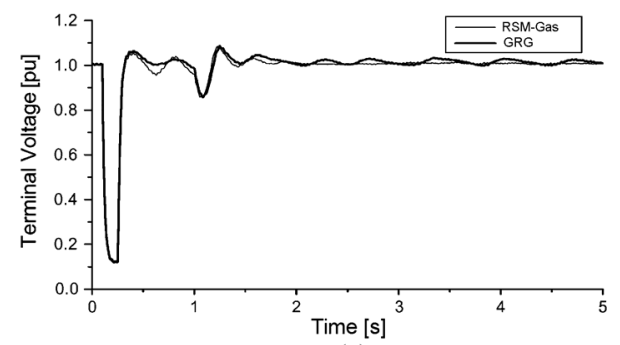

(a)

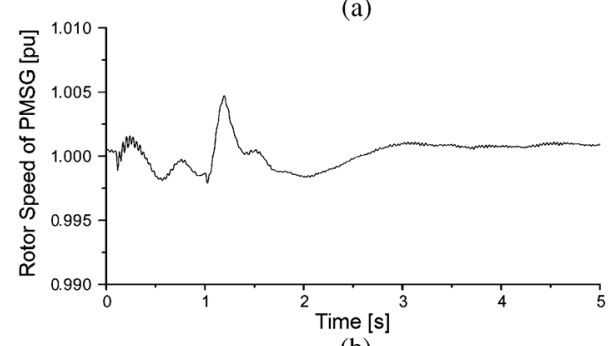

(b)

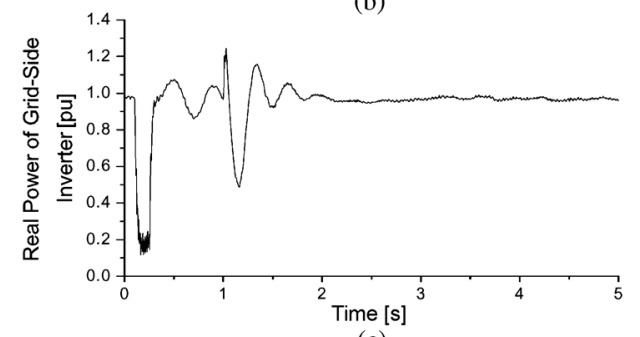

(c)

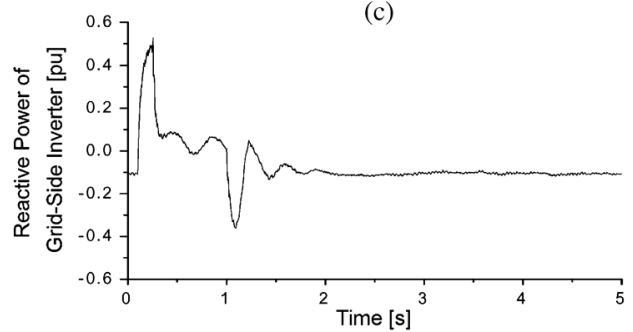

(d)

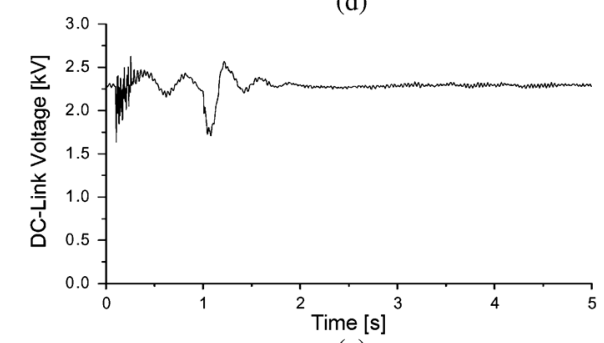

(e)

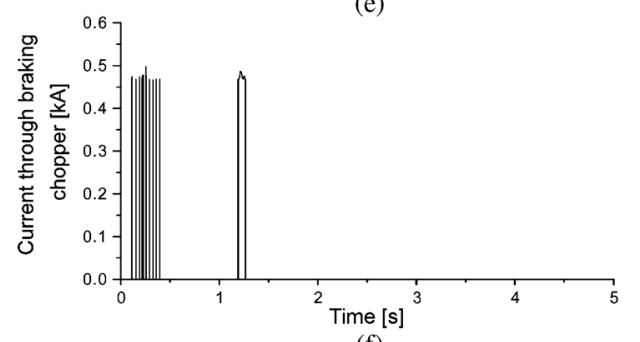

(f)

Fig. 9. Responses for $3 \mathrm{LG}$ fault. (a) Terminal voltage of the grid. (b) Rotor speed of PMSG. (c) Real power of grid-side inverter. (d) Reactive power of grid-side inverter. (e) DC voltage across two capacitor legs of 3L NPC inverter. (f) Current through braking chopper.

line are opened at $0.25 \mathrm{~s}$, and at $1.0 \mathrm{~s}$, the CBs are reclosed. It is also considered that the reclosing of the CBs is unsuccessful due to a permanent fault. Therefore, the CBs are reopened at

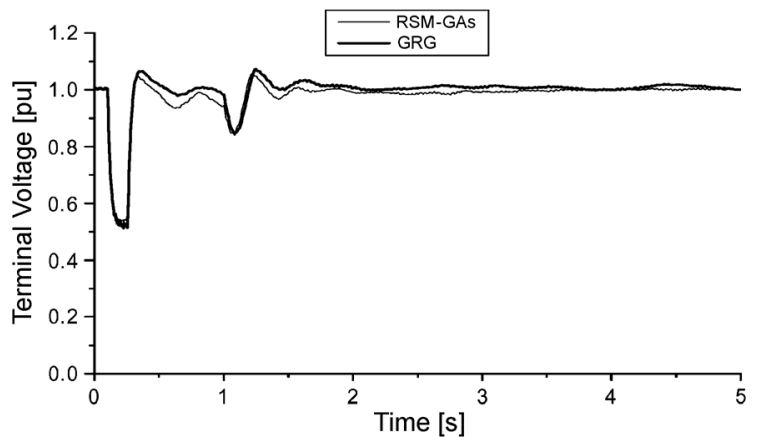

Fig. 10. Response of the grid-side terminal voltage for $1 \mathrm{LG}$ fault

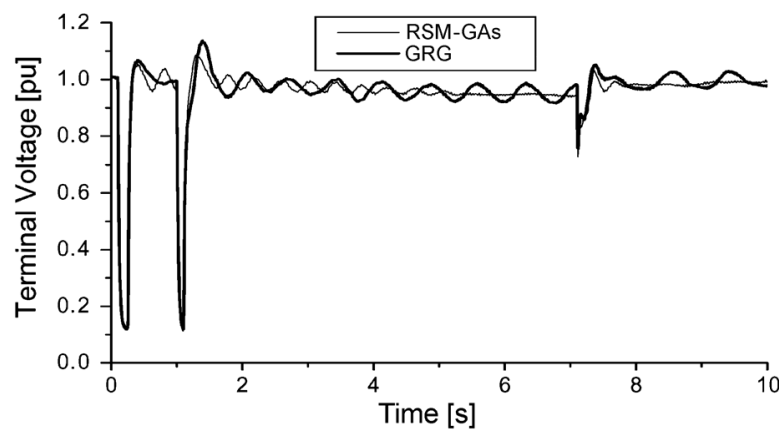

(a)

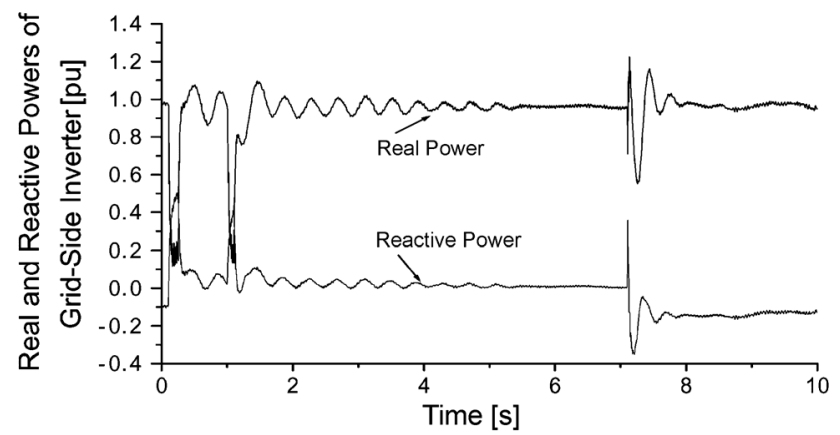

(b)

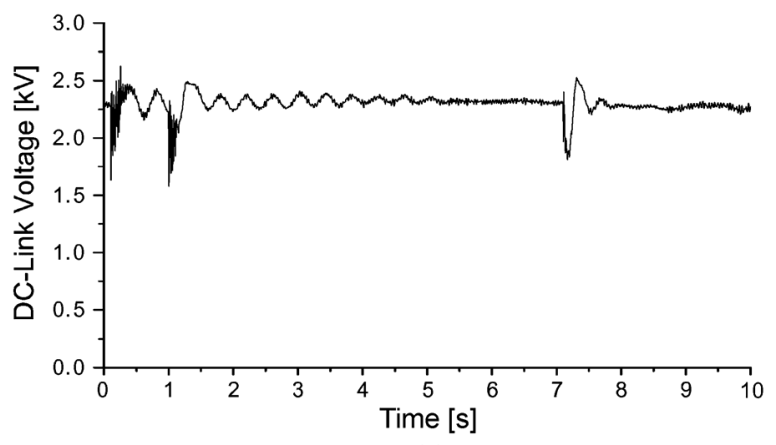

(c)

Fig. 11. Responses for permament 3LG fault. (a) Terminal voltage of the grid. (b) Real and reactive power of grid-side inverter. (c) DC voltage across two capacitor legs of 3L NPC inverter.

$1.1 \mathrm{~s}$. It is assumed that the circuit breaker clears the line when the current through it crosses the zero level. The permanent fault is assumed to be cleared at $7.0 \mathrm{~s}$, and at $7.1 \mathrm{~s}$, the CBs are reclosed again. The response of terminal voltage of the grid is shown in Fig. 11(a). It is seen from Fig. 11(a) that the terminal voltage response when GAs-RSM is used, is a better damped 
response than that obtained when the GRG approach is considered. Further, during the permanent fault period, the voltage can be maintained within the permitted value of wind farm grid code. After the clearance of the permanent fault, the voltage is returned back to the prefault level quickly and the system back to the normal conditions as both transmission lines are in operation. The responses of real and reactive powers of the grid-side inverter are shown together in Fig. 11(b). Fig. 11(c) shows the dc-link voltage response. Therefore, the optimal designed parameters of the controllers used in the frequency converter obtained from GAs-RSM work superbly to improve the FRT of wind farms, even in the case of permanent fault.

\section{CONCLUSION}

This paper has attempted to present an approach to optimally determine the controller parameters which control, in general, the switching of the frequency converter used in VSWT-driven PMSG to achieve FRT as per recent wind farm grid code. RSM and GA techniques are proposed to determine the controller parameters, in a precise way. It is found that the system can achieve the FRT of the wind farm successfully using the determined parameter in the case of sever three-line to ground fault, as well as the permanent fault due to unsuccessful reclosing of circuit breakers. The parameters even worked well for the unsymmetrical fault condition. It should be noted that, GAs-RSM have given better damping performance over the GRG approach to achieve the FRT capability of the wind farm. The detail of the optimum design procedure is discussed, which can be applied to other inverter/converter topology used widely in variable speed wind energy conversion systems. The proposed methodology is even suitable to other power system related applications such as FACTS devices, the voltage source converter-based HVDC system, and so on, especially in the cases where it is difficult to determine the suitable transfer function of a complex and larger system. Finally, it is concluded that RSM and GA-based optimization technology might be a good choice for optimum design of controller parameters.

\section{REFERENCES}

[1] Global Wind Energy Council (GWEC), Wind is a Global Power Source Global Trend-GWEC [Online]. Available: http://www.gwec.net

[2] E. On Netz, Grid Code, High and Extra-High Voltage Apr. 2006 [Online]. Available: www.eon-netz.com/

[3] B. Singh and S. N. Singh, "Wind power interconnection into the power system: A review of grid code requirements," Electr. J., vol. 22, no. 5, pp. 54-63, 2009.

[4] M. Molinas, J. A. Suul, and T. Undeland, "Low voltage ride through of wind farms with cage generators: STATCOM versus SVC," IEEE Trans. Power Electron., vol. 23, no. 3, pp. 1104-1117, May 2008.

[5] E. S. Abdin and W. Xu, "Control design and dynamic performance analysis of a wind turbine induction generator unit," IEEE Trans. Energy Convers., vol. 15, no. 1, pp. 91-96, Mar. 2000.

[6] J. Tamura, T. Yamazaki, R. Takahashi, S. Yonaga, H. Kubo, and Y. Matsumura, "Analysis of transient stability of wind generators," in Proc. Int. Conf. Electrical Machines (ICEM), Bruges, Belgium, 2002, no. 148.

[7] S. M. Muyeen, M. Hasan Ali, R. Takahashi, T. Murata, J. Tamura, M. Kubo, A. Kuwayama, and T. Matsumoto, "Low voltage ride through capability enhancement of wind turbine generator system during network disturbance," IET Renew. Power Generat., vol. 3, no. 1, pp. 65-73, 2009.

[8] M. Kayikci and J. V. Milanovic, "Reactive power control strategies for DFIG-based plants," IEEE Trans. Energy Convers., vol. 22, no. 2, pp. 389-396, Jun. 2007.
[9] E. Muljadi, C. P. Butterfield, B. Parsons, and A. Ellis, "Effect of variable speed wind turbine generator on stability of a weak grid," IEEE Trans. Energy Convers., vol. 22, no. 1, pp. 29-36, Mar. 2007.

[10] J. Hu, Y. He, L. Xu, and B. W. Williams, "Improved control of DFIG systems during network unbalance using PI-R current regulators," IEEE Trans. Ind. Electron., vol. 56, no. 2, pp. 439-451, Feb. 2009.

[11] A. K. Jain and V. T. Ranganathan, "Wound rotor induction generator with sensorless control and integrated active filter for feeding nonlinear loads in a stand-alone grid," IEEE Trans. Ind. Electron., vol. 55, no. 1, pp. 218-228, Jan. 2008.

[12] T. Sun, Z. Chen, and F. Blaabjerg, "Transient stability of DFIG wind turbines at an external short circuit fault," Wind Energy, vol. 8, no. 3, pp. 345-360, 2005.

[13] S.-K. Kim and E.-S. Kim, "PSCAD/EMTDC-based modeling and analysis of a gearless variable speed wind turbine," IEEE Trans. Energy Convers., vol. 22, no. 2, pp. 421-430, Jun. 2007.

[14] A. Yazdani and R. Iravani, "A neutral-point clamped converter system for direct-drive variable speed wind power unit," IEEE Trans. Energy Convers., vol. 21, no. 2, pp. 596-607, Jun. 2006.

[15] E. Echenique, J. Dixon, R. Cardenas, and R. Pena, "Sensorless control for a switched reluctance wind generator, based on current slopes and neural networks," IEEE Trans. Ind. Electron., vol. 56, no. 3, pp. 817-825, Mar. 2009.

[16] N. A. Cutululis, E. Ceanga, A. D. Hansen, and P. Sørensen, "Robust multi-model control of an autonomous wind power system," Wind Energy, vol. 9, no. 5, pp. 399-419, 2006.

[17] K. Tan and S. Islam, "Optimum control strategies in energy conversion of PMSG wind turbine system without mechanical sensors," IEEE Trans. Energy Convers., vol. 19, no. 2, pp. 392-399, Jun. 2004.

[18] M. Chinchilla, S. Arnaltes, and J. C. Busgos, "Control of permanentmagnet synchronous generators applied to variable-speed wind-energy systems connected to the grid," IEEE Trans. Energy Convers., vol. 21, no. 1, pp. 130-135, Mar. 2006.

[19] J. Zhang, M. Cheng, and Z. Chen, "Nonlinear control for variable speed wind turbines with permanent magnet generators," in Proc. Int. Conf. Electrical Machines and Systems (ICEMS), Seoul, Korea, Oct. 2007, pp. 324-326.

[20] S. Morimoto, T. Nakamura, and Y. Takeda, "Power maximization control of variable speed wind generation system using permanent magnet synchronous generator," IEEJ Trans. Power Electron., vol. 123-B, no. 12, pp. 1573-1579, 2003.

[21] S. M. Muyeen, R. Takahashi, T. Murata, J. Tamura, and M. H. Ali, "Transient stability analysis of permanent magnet variable speed synchronous wind generator," in Proc. ICEMS, Seoul, Korea, Oct. 2007, pp. 288-293.

[22] S. M. Muyeen, R. Takahashi, T. Murata, and J. Tamura, "Transient stability enhancement of variable speed wind turbine driven PMSG with rectifier-boost converter-inverter," in Proc. ICEM, Portugal, Sep. 6-9, 2008

[23] P. Vas, Electrical Machines and Drives - A Space Vector Theory Approach. New York: Oxford Univ. Press, 1992.

[24] T. J. E. Miller, Brushless Permanent Magnet and Reluctance Motor Drives. New York: Oxford Univ. Press, 1989.

[25] J. Ribrant and L. M. Bertling, "Survey of failures in wind power systems with focus on Swedish wind power plants during 1997-2005," IEEE Trans. Energy Convers., vol. 22, no. 1, pp. 167-173, Mar. 2007.

[26] J. I. Leon, S. Vazquez, R. Portillo, L. G. Franquelo, J. M. Carrasco, P. W. Wheeler, and A. J. Watson, "Three-dimensional feedforward space vector modulation applied to multilevel diode-clamped converters," IEEE Trans. Ind. Electron., vol. 56, no. 1, pp. 101-109, Jan. 2009.

[27] S. Heier, Grid Integration of Wind Energy Conversion System. Chicester, U.K.: Wiley, 1998.

[28] J. G. Slootweg, S. W. H. De Hann, H. Polinder, and W. L. Kling, "General model for representing variable speed wind turbines in power system dynamic simulations," IEEE Trans. Power Syst., vol. 18, no. 1, pp. 144-151, Feb. 2003.

[29] D. J. Trudnowski, A. Gentile, J. M. Khan, and E. M. Petritz, "Fixedspeed wind-generator and wind-park modeling for transient stability studies," IEEE Trans. Power Syst., vol. 19, no. 4, pp. 1911-1917, Nov. 2004.

[30] S. M. Muyeen, T. Murata, and J. Tamura, Stability Augmentation of a Grid Connected Wind Farm. United Kingdom: Springer, Oct. 2008.

[31] H. M. Hasanien, A. S. Abd-Rabou, and S. M. Sakr, "Design optimization of transverse flux linear motor for weight reduction and performance improvement using response surface methodology and genetic algorithms," IEEE Trans. Energy Convers., vol. 25, no. 3, pp. 598-605, Sep. 2010.

[32] "PSCAD/EMTDC Manual," Manitoba HVDC Research Center, 1994. 
[33] H. M. Hasanien, "Particle swarm design optimization of transverse flux linear motor for weight reduction and improvement of thrust force," IEEE Trans. Ind. Electron., vol. 58, no. 9, pp. 4048-4056, Sep. 2011.

[34] D. E. Goldbert, Genetic Algorithm in Search, Optimization and Machine Learning. Reading, MA: Addison-Wesley, 1989.

[35] H. A. Cabral and M. T. de Melo, "Using genetic algorithms for device modeling," IEEE Trans. Magn., vol. 47, no. 5, pp. 1322-1325, May 2011.

[36] P. Mathews, Design of Experiments With MINITAB. Milwaukee: American Society of Quality, Quality press, 2005

[37] MATLAB Optimization Toolbox. U.K.: The Math Works Press, Aug. 2010, Release $2010 \mathrm{~b}$.

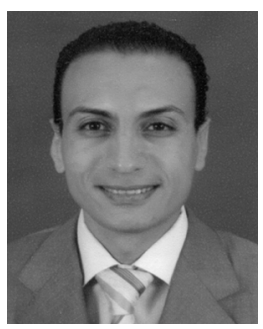

Hany M. Hasanien (M'09-SM'11) was born in Cairo, Egypt, on May 20, 1976. He received the B.Sc., M.Sc., and Ph.D. degrees in electrical engineering from Ain Shams University, Faculty of Engineering, Cairo, Egypt, in 1999, 2004, and 2007, respectively.

$\mathrm{He}$ is an Assistant Professor at the Electrical Power and Machines Department, Faculty of Engineering, Ain Shams University. Currently, he is on leave as Assistant Professor at the Electrical Engineering Department, College of Engineering, King Saud University, Riyadh, S.A. His research interests include machine design, modern control techniques, electrical drives, and artificial intelligence applications on electrical machines and renewable energy systems.
Dr. Hasanien is a Senior Member of the IEEE Power and Energy Society (PES) and the Industrial Electronics Society (IES). Recently, he has published a book (coauthored with Dr. S. M. Muyeen and Prof. J. Tamura), Switched Reluctance Machine, which received the Praise Worthy Prize, Feb. 2010. His biography has been included in Marquis Who's Who in the World for its 28th edition, 2011.

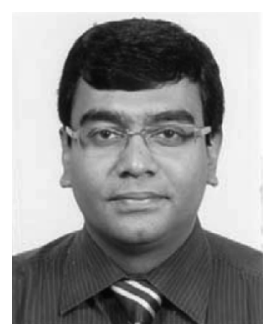

S. M. Muyeen (S'03-M'08-SM'12) received the B.Sc. Eng. degree from Rajshahi University of Engineering and Technology (RUET), Bangladesh, formerly known as Rajshahi Institute of Technology, in 2000, and the M.Sc. Eng. and Dr. Eng. degrees from Kitami Institute of Technology, Japan, in 2005 and 2008, respectively, all in electrical and electronic engineering. His Ph.D. research work focused on wind farm stabilization from the viewpoint of LVRT and frequency fluctuation.

After completing his Ph.D. program, he worked as a Postdoctoral Research Fellow under the versatile banner of Japan Society for the Promotion of Science (JSPS) from 2008 to 2010 at the Kitami Institute of Technology, Japan. At the present, he is working as Assistant Professor in the Electrical Engineering Department, Petroleum Institute, Abu Dhabi. His research interests are power system stability and control, electrical machine, FACTS, energy storage systems (ESS), renewable energy, and HVDC systems. He has authored, coauthored, and edited four books in the areas of electric machines and renewable energy. 